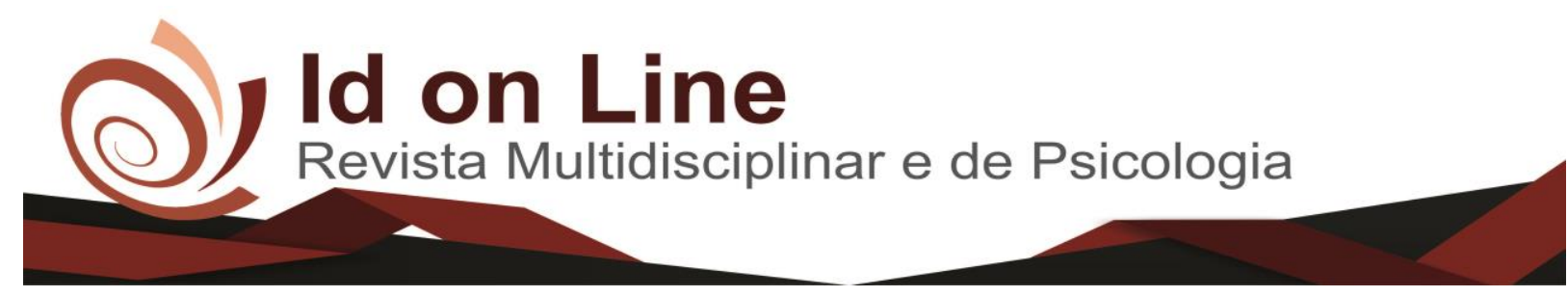

Comment

\title{
Uma Análise da Aprendizagem da Matemática na Educação
}

Janiere Ribeiro de Souza ${ }^{1}$; João Everaldo Alves Felizardo ${ }^{2}$

Resumo: Este artigo busca mostrar os processos de aprendizagem da matemática na educação infantil. Desta forma, procuramos discutir estratégias para uma pedagogia que valorize os jogos matemáticos. No âmbito da Educação Infantil, o jogo estimula o desenvolvimento de suas atividades cognitivas e manipulativas. Em função disso percebemos que a ludicidade é de grande importância para o futuro dos mesmos, pois ela propõe um grande avanço intelectual. Os jogos e brincadeiras desperta na criança um bom nível de conhecimento, sendo este de grande favorecimento para uma educação de qualidade..Para atingir os objetivos propostos em explorar ideias referentes aos números utilizados tratar-se-á como base da reflexão as teorias dos seguintes pensadores: Kishimoto (2009), DIAS (2010), BICUDO (1999).

Palavras chaves: Jogos Matemáticos. Brincadeiras. Aprendizagem.Estratégias.

\section{An Analysis of the Mathematics Learning in Education}

\begin{abstract}
This article entitled An analysis of mathematical learning of the child in early childhood education. It seeks to show the learning processes of mathematics in early childhood education. In this way, we try to discuss strategies for a pedagogy that values mathematical games. In the context of Early Childhood Education, the game stimulates the development of its cognitive and manipulative activities. Because of this we realize that playfulness is of great importance for their future, since it proposes a great intellectual advance. The games and games awaken the child a good level of knowledge, this being a great favor for a quality education. In order to achieve the proposed goals of exploring ideas concerning the numbers used, the theories of the following thinkers will be based on reflection: Kishimoto (2009), DIAS (2010), and BICUDO (1999).
\end{abstract}

Key words: Mathematical games. Just kidding.Learning. Development.

\section{Introdução}

A escolha desse tema nasceu da inquietação em melhor compreender o processo de aprendizagem da educação infantil, como espaço privilegiado da aprendizagem onde, é possível assimilar o aprender com o brincar.

\footnotetext{
${ }^{1}$ Faculdade de Ciências Humanas do Sertão Central - FACHUSC, Salgueiro - PE, Brasil. Email. janiere@ hotmail.com

${ }^{2}$ Graduação em Letras pela Faculdade de Ciências Humanas do Sertão Central / Ensino Fundamental e Médio; Coordenador Pedagógico Efetivo na Sec. Municipal de Educação na Cidade de Serrita-PE, na Área de Linguagens e Códigos. Contatos: (87) 99911-6674; (87) 981299556.
} 
Este artigo aborda a importância dos jogos e brincadeiras para o desenvolvimento integral da criança e não apenas como entretenimento, mas uma atividade que possibilita a aprendizagem de várias habilidades.

Tem como objetivo esclarecer a importância do brincar no contexto da etapa educacional, mostrando que o lúdico é considerado como importante fator no processo de ensino aprendizagem. É de grande importância o ensino e a aprendizagem da matemática na educação infantil, pois através dela os discentes irão descobrir o mundo, modificar sua história.

É através dos jogos e brincadeiras que os educandos perdem o medo e interagem no desenvolvendo de várias habilidades, tais como: cantar, dançar, interpretar, aprendendo novas brincadeiras, entre outros, com isso, o seu aprendizado torna-se dinâmico, pois as crianças mais tímidas conseguem realizar as atividades lúdicas interagindo de forma peculiar a criatividade das aulas.

A educação infantil é a etapa mais importante do ensino, é onde a criança está se moldando para acolher os conhecimentos, nesse ponto, é importante um ensino de matemática que seja dinâmico, simples e moderno que atenda às necessidades dos educandos que seja uma matemática para o uso constante nos afazeres simples da vida e nas suas brincadeiras.

O ensino nas escolas públicas municipais precisa, de certa forma, ser pautadas na compreensão e na prática, porém não é fácil se trabalhar desta forma com as crianças se não houver uma prática lúdica envolvente e atraente que busque uma inovação pertinente ao seu ensino e a carência que os alunos possuem.

Partindo desse pressuposto, este artigo veio abordar sobre estratégias viáveis para o ensino da matemática e como os alunos devem aprender os conteúdos de forma prazerosa e envolvente para que assim tenham o gosto e prazer de estar em sala de aula.

Entender o lúdico como parte integrante para o sucesso do ensino da matemática é abrir horizontes pertinentes à realidade encontrada nas escolas, ver e entender cada turma, buscar materiais, criar mecanismos em que apontem para um bom ensino, só o lúdico pode satisfazer essa necessidade juntamente com a sua inovadora do professor em sala de aula.

O papel do professor é muito importante e deve estar em consonância com o currículo vigente, usar os elementos que tem e buscar outras formas introduzir os educandos num ensino transformador.

Este artigo foi produzido por meios de pesquisas bibliográficas com base em Kishimoto, (2009) "Através do jogo, temos a possibilidade de abrir espaço para a presença do lúdico na 
escola, não só como sinônimo de recreação e entretenimento". Buscando de mostrar a realidade existente entre a ação docente e o aprendizado dos alunos.

\section{Aprender e ensinar matemática}

O ensino e a aprendizagem da matemática com os jogos ajudam os estudantes a aprender de forma significativa. Embora as crianças falem que aprender matemática é muito difícil, mas através do lúdico se torna prazerosa desafiadora e instigante. Os jogos exercem um papel importante na construção de conceitos matemáticos, com isso a ação docente deve está aberta a incorporar várias ações de criatividades para uma inovação que possa de fato atingir os objetivos necessários a uma educação de qualidade, prazerosa e cheia de encantos.

A aprendizagem na educação infantil se dá a partir da curiosidade da criança e crescem em função dos tipos de experiências vivenciadas nas aulas de matemática. Experiências desafiadoras incentivam as crianças, a levantar hipótese, na construção de argumentos mais sofisticados.

Segundo Soares (2009, pg. 12), “compreender como os indivíduos aprendem continua sendo um grande desafio. Sabemos que as experiências de vida têm peso na aprendizagem, bem como características próprias de cada pessoa.

A verdadeira educação é aquela que instiga o desejo do indivíduo de explorar, observar, trabalhar, jogar. A aprendizagem do aluno é responsabilidade do estado, município, da escola e da família. Esses, juntos, devem buscar de acordo com suas funções, condições básicas para que, os educandos possam vir a construir conhecimentos de forma significativa. O jogo, com seu caráter lúdico, para o ser humano em qualquer idade. Consequentemente proporcionar situações com jogos é investir no prazer, no desafio e no melhor desempenho dos alunos.

Com a prática do lúdico podem envolver as famílias no contexto escolar promovendo ações educativas que coloquem os pais ou os responsáveis para juntos com as crianças desenvolverem brincadeiras, jogos, danças e outros. Sendo assim, com a participação familiar dentro da escola, à educação será eficaz.

Cabe a gestão escolar junto às secretarias de educação dos municípios oferecerem materiais necessários e constantes formações continuadas aos docentes para que a cada semestre possam de fato aprimorarem seus conhecimentos para a sua atuação docente com mais vigor proporcionando ações educativas mais claras e objetivas. 
Os jogos matemáticos desenvolvem o raciocínio lógico das crianças e suas habilidades, levando o indivíduo a idealizar a matemática de forma prazerosa, portanto, o educando utilizando os jogos matemáticos encontra equilíbrio entre o real e o imaginário, e amplia não só seu conhecimento matemático, mais outros conhecimentos, principalmente no uso da língua falada e escrita, aprende regras e disciplina entre outros.

O educador pode proporcionar de forma prazerosa aos educandos a vivenciarem uma matemática com uma aprendizagem satisfatória, se o profissional de educação estiver preparado com suas ações abertas ao dinamismo e a modernidade, para assim compartilhar seus conhecimentos.

Segundo Alsina, (2009, pg37): “os conhecimentos e as habilidades numéricas adquiridas devem aplicar-se a situações reais do cotidiano, porém não se trata só de aprender e depois aplicar, mas também de aprender aplicando tais conhecimentos e habilidades.

O jogo tem um papel importantíssimo na Educação Matemática, cabe à escola juntamente com seus profissionais organizarem estratégias de ensino para atuarem com mais respaldo pedagógico para assim tornar esse ensino matemático proveitoso e atraente. Quando permite a criança a entrar no mundo imaginário, por meio de objetos simbólicos dispostos intencionalmente, a função pedagógica subsidia o desenvolvimento integral da criança.

Através do jogo, temos a possibilidade de abrir espaço para a presença do lúdico na escola, não só como sinônimo de recreação e entretenimento. Muito mais do que um simples material instrucional, ele permite o desenvolvimento da criatividade, da iniciativa e da intuição. Enfim do prazer elemento indispensável para que ocorra uma aprendizagem significativa. (KISHIMOTO, 2009, p.22)

O autor afirma sem dúvida, que o jogo é uma ferramenta importantíssima para o aprendizado dos alunos na pratica do ensino de matemática, com ele assume toda uma postura social, cultural de recreação, de contato físico e emocional de uma criança, onde ela se descobre e se desenvolve de forma significativa.

Nesse sentido, podemos entender que o jogo é sem dúvida, uma ferramenta importante para o aprendizado das crianças, desenvolvendo nelas criatividades, competitividade, confiança, fazendo com que as mesmas participem ativamente de cada atividade sem ter medo de errar. Dessa forma cria-se um ambiente para o trabalho em grupo, em que os educandos aprendem a compartilhar dividir e ajudar o próximo em qualquer situação. 


\section{O Lúdico como parte integrante para o sucesso do ensino da matemática}

O lúdico no ensino da matemática, na educação infantil, além de dinâmico faz com que os alunos sintam o prazer em aprender, porém eles se identificam com as brincadeiras e jogos, o primeiro contato com o lúdico faz com que os alunos participem ativamente das aulas, é importante que o docente busque conhecer a realidade dos alunos para poder trabalhar bem o lúdico, colher informações de cada um a respeito de sua cultura, seu modo de vida, para assim poder atuar melhor no ambiente educativo.

Kishimoto acredita que o jogo pode ter duas funções utilizadas como elemento pedagógico na educação, uma que propicia a diversão, o prazer e até mesmo o desprazer, quando escolhido voluntariamente, e uma função educativa, onde o jogo serve para complementar o conhecimento do indivíduo. Isso caracteriza o jogo educativo. (. KISHIMOTO 1993, p.21)

Segundo Kishimoto (1994), o jogo estimula a exploração e a solução de problemas e, por ser livre de expressões cria um clima adequado para a investigação e a busca de soluções, daí cada indivíduo vai refletor sus vida, seus problemas e poderá de certa forma atuar melhora na administração de seus problemas.

Os jogos, na Educação Infantil, para as crianças constituem-se em atividades que trazem enormes benefícios para a aprendizagem, sendo assim satisfazendo as necessidades do ensino, mas isso só será possível se houver um planejamento que esteja casado à realidade dos educandos e que a escola tenha uma estrutura peculiar, como: Uma brinquedoteca, um espaço atrativo para a socialização dos jogos, monitores que conheçam a objetividade de cada atividade entre outros.

A brincadeira para a criança é a mais valiosa oportunidade de aprender a conviver com pessoas muito diferentes entre si, de compartilhar ideias, regras, objetos e brinquedos, alegrias e tristezas. Na Educação Infantil, as brincadeiras devem fazer parte da rotina diária dessas instituições e devem ser utilizadas em diferentes momentos do dia, com isso haverá uma rotina que se tornara regra de vida, proporcionando um aprendizado no cotidiano das crianças no seu habitar-te natural, ou seja, em sua família.

Sendo a Educação Infantil uma etapa que possibilita um ensino dinâmico e contextualizado que favorece a construção de saberes nas relações do cotidiano, principalmente no que diz respeito ao conhecimento matemático, pois a matemática está presente nas situações do dia a dia na forma como a criança organiza seu pensamento, nas brincadeiras e jogos infantis. 
Falar sobre o ensino da matemática na educação infantil é muito desafiador, pois o ensino está de forma peculiar ao contex to e não mais ao calcular simplesmente, o ensino carece de contextualização, de ser mais moderno e dinâmico.

A matemática é uma ciência muito importante para a comunidade, está presente em todos os momentos da vida de um indivíduo, e deve ser mostrado que ela é usada em todas as etapas de nossas vidas, e não existe vida social sem o uso da matemática.

A escola por sua vez, tem um papel muito importante, o de conduzir o ensino significativo para que cada discente aprenda a dominá-lo, para isso, com as novas perspectivas do ensino moderno em que levou ao educando a refletir o que estudou, levando em consideração o conhecimento do docente em inovar sua prática, produzir mecanismos em que coloque o seu pupilo no centro do aprender com o ensino integrando a sua realidade.

O profissional de educação deve ser antes de tudo um mediador, capaz de perceber sua ação transformadora e produzir de forma ampla, associada ao currículo o que obtendo os objetivos que quer necessite ser alcançado.

A sua ação deve levar em conta as suas ações profissionais e a partir daí garantir para o educando uma aprendizagem significativa e de forma prazerosa para que essas crianças possam interagir de forma significativa.

A ideia central é que as atividades planejadas devem contar com a participação ativa das crianças garantindo a mesma construção das nações de tempo e espaço, possibilitando-lhes a compreensão do modo com as situações são organizadas e, sobretudo, permitindo ricas e variadas indicações sociais (DIAS, 2010, p.13)

Ao entrar na escola, a criança amplia sua vida afetiva e estabelece novas relações sociais tanto com os educadores, quanto com as outras crianças, ou seja, com a comunidade escolar de uma forma geral. Dessa forma, as instituições de ensino devem criar um ambiente saudável para as relações sociais e para o processo de ensino aprendizagem. Quando a criança brinca com jogos de regras ela aprende, ela aprende a brincar com o outro, aprende a ganhar ou perder ó brincar é fundamental para enfrentar diversas situações do cotidiano, isso faz com que o educando tenha um arsenal de informações para que possa interagir com as outras crianças.

O brincar é importante para a criança expressar significações simbólicas, ao assumir papéis, ao usar objetos com outras finalidades para expressar significações à criança entra no processo simbólico. O brincar auxilia no desenvolvimento mental e lógico do educando, a aprendizagem também ocorre quando o indivíduo no brincar aprende roteiro que subsidia a brincadeira. 
O referencial Curricular para o ensino infantil aponta que:

\begin{abstract}
Nessa perspectiva, de acordo com os Referenciais Curriculares Nacionais para a Educação Infantil (RCNEI): Brincar é uma das atividades fundamentais para o desenvolvimento da identidade e da autonomia. O fato de a criança, desde muito cedo, poder se comunicar por meio de gestos, sons e mais tarde representar determinado papel na brincadeira faz com que ela desenvolva sua imaginação. Nas brincadeiras as crianças podem desenvolver algumas capacidades importantes, tais como a atenção, a imitação, a memória, a imaginação. Amadurecem também algumas capacidades de socialização, por meio da interação e da utilização e experimentação de regras e papéis sociais (BRASIL, 1998, p. 22).
\end{abstract}

Sendo assim, é percebível o quão é importante o lúdico nas brincadeiras e jogos na educação infantil, desde muito cedo as crianças interagem com o mundo em que vive através do brincar na imitação, na memorização de objetos, de nomes que ensinamos, elas desenvolvem uma aprendizagem significativa, o desenvolvimento cognitivo como ser social no meio em que vive, interagindo com os outros de uma maneira simples e prazerosa.

De acordo com (RCNEI, 1998), as noções matemáticas abordadas na educação infantil correspondem e jogos que possam interessar à criança pequena constituem-se rico contexto em uma variedade de brincadeiras e jogos, principalmente aqueles classificados como de construção e de regras. Vários tipos de brincadeiras que ideias matemáticas podem ser evidenciadas pelo adulto por meio de perguntas, observações e formulação de propostas. São exemplos disso cantigas, brincadeiras como a dança das cadeiras, quebra-cabeças, labirintos, dominós, dados de diferentes tipos, jogos de encaixe, jogos de cartas etc.

Desta forma fica claro que as crianças aprendem melhor com o lúdico, possibilitando assim o desenvolvimento $\mathrm{e}$ as habilidades, de maneira dinâmica que favorece o desenvolvimento o respeito, a convivência com o outro. O jogo pode ser trabalhado individualmente, em duplas ou em grupos, mas deve ser algo em que crie um espaço de confiança e criatividade para ser desenvolvida de maneira agradável e espontânea.

Os jogos são para as crianças da Educação Infantil, constituem-se em atividades que trazem grandes benefícios para a aprendizagem satisfazendo as necessidades do ensino, agora o que os professores devem ter em mente é: Como fazer? O que temos para fazer? Que objetivos devem ser alcançados? Dessa forma, será conciliada todas as ações integradas da escola e do planejamento com base no currículo da educação infantil de forma moderna.

O policiamento a essas ações é considerado imperioso ao sucesso da educação partindo da observação, adequação e inclusão, parte relevante a ação transformadora da educação.

Vejamos é essa outra importante afirmação do Referencial: 
Os jogos espaciais permitem às crianças observarem as figuras e suas formas, identificar propriedades geométricas dos objetos, fazer representações, modelando, compondo, decompondo ou desenhando. Um exemplo desse tipo de jogo é a modelagem de dois objetos em massa de modelar ou argila, em que as crianças descrevem seu processo de elaboração. Pelo seu caráter coletivo, os jogos e as brincadeiras permitem que o grupo se estruture que as crianças estabeleçam relações ricas de troca, aprendam a esperar sua vez, acostumem se a lidar com regras, conscientizando-se que podem ganhar ou perder. (BRASIL,1998, p.235).

Com essa prática amplia o olhar da criança em observar e ver o mundo, e pode despertar no aluno os seus dons de pinturas, desenhos, formas geométricas e uma nova forma de ver o mundo ao seu redor e perceber como é sua comunidade, cidade e povoados. Com isso seu poder do conhecimento torna-se amplo, dinâmico, prazeroso, despertando os sonhos e analisando as realidades.

\section{O Papel do Professor}

O professor como mediador do conhecimento deve ser crítico e reflexivo para melhor lhe dar com as crianças. Embora nos cursos de formação superior os professores não aprendem como se trabalhar uma matemática dinâmica com crianças da educação infantil e nem muito menos nos cursos de formação, o professor tem desempenhado um importante papel na sociedade.

De acordo com os Parâmetros Curriculares Nacionais de Matemática (1998), à medida que se redefine o papel do aluno diante do saber, considerando-o como protagonista da construção de sua aprendizagem, é preciso redimensionar o papel do professor que ensina matemática no ensino fundamental.

Os cursos de formação superior não formam professores, mas sim as experiências, as convivências com o meio em que vive suas experiências, suas vivências, sua constante luta. Embora não se invista tanto na formação dos professores, não se têm uma formação de qualidades, os professores, por sua vez tenta dar o melhor de si. Exemplo disso é a professora Kishimoto, que vem inovando a cada dia procurando ensinar aos professores como eles devem ensinar as crianças de uma forma prazerosa, e significativa não só nas aulas de matemática, mas também nas outras disciplinas, deixando bem claro que a criança no brincar é que se aprende.

É por isso que os professores mais velhos na profissão ficam apreensivos em trabalhar com as crianças de forma dinâmica, pois eles acham que a criança só aprende se for à forma 
tradicional; professor e quadro. O professor trabalhando de forma dinâmica a aprendizagem tem sido mais significativa e as aulas prazerosas onde as crianças sentem prazer em ir para escola. A turma deve interagir junto com o professor, confeccionar materiais que irão utilizar na aula isso é muito significativa para criança, ela aprende de melhor forma interagindo com o outro, a criança não só aprende na decodificação de símbolos, mas no ouvir ao interagir com outras crianças.

Se o brincar facilita a aprendizagem, então é preciso que o educador seja a favor do lúdico, pois nada será possível se os professores não se interessassem por essa forma de educação. O profissional precisa aumentar à criatividade, o entusiasmo, a alegria e o observar, as crianças no decorrer do brincar, é necessário que o educador entenda o brincar da criança.

O que se mostra mediante o exposto é na verdade a importância da ação do professor de educação infantil mediante as diversas culturas existentes no corpo de uma sala de aula, para que ele possa de certa forma inovar sua ação respeitando e acolhendo cada peculiaridade mediante suas decisões frente à aplicabilidade de suas aulas.

O professor deve conhecer os elementos teóricos envolvidos no processo de construção de conceitos para que compreenda melhor alguns aspectos da aprendizagem das crianças, dessa forma, o papel do professor é fundamental para desmitificar a ideia de que ser criativo é um dom divino. Ele, o professor, exerce o papel de mediador privilegiado no processo ensinoaprendizagem, ao crescimento do seu aluno e ao desenvolvimento das habilidades criativas.

\footnotetext{
A educação matemática permite a compreensão do que se faz ao educar, das propostas pedagógicas, do sentindo que fazem as teorias que estudam assuntos da educação. E, preponderantemente, um fazer mediativo que leva ao autoconhecimento, á autocrítica e, portanto, ao conhecimento e crítica do mundo (BICUDO, 1999, p.25).
}

Bicudo (1999), afirma que a educação matemática permite um grande leque de conhecimentos ao educar, mediante as propostas pedagógicas, mediando um conhecimento real e atuante onde, de certa forma, os educandos além de conhecerem a matemática vão poder ver e interpretar o mundo a sua volta.

Os referenciais curriculares da educação infantil (1998) retratam que o professor deve proporcionar o jogo e a brincadeira em um ambiente que estimule a ludicidade em função de seus objetivos. Sendo assim o professor desempenha um importante papel no transcorrer das brincadeiras se conseguir discernir os momentos em que deve observar em que deve intervir na coordenação da brincadeira ou em que deve integrar-se como participante das mesmas. 
Por meio das brincadeiras os professores podem assistir e constituir uma visão dos processos de desenvolvimento das crianças em conjunto e de cada uma em particular, registrando suas capacidades de uso das linguagens assim como suas capacidades sociais e dos recursos afetivos e emocionais que dispõem sabemos, portanto, que o processo de formação das crianças é complexo, pois envolve atividades intelectuais e mentais por partes da criança por isso para aprender um conceito é preciso ter, além das informações recebidas do ambiente, capacidades de abstração, cooperação, memória, concentração e atenção.

Brincar implica troca com o outro, trata-se de uma aprendizagem social. Nesse sentindo, a presença do professor é fundamental, pois será ele quem vai mediar as relações, favorecer as trocas e parcerias, promover a interação, planejar e organizar ambientes instigantes para que o brincar possa se desenvolver (BRASIL, 2005, p.50).

Sabendo- se que o professor é quem media o saber e este deve estar preparado para essa forma de ensino, tornando as aulas mais atrativas, de forma em que os educandos possam interagir com os outros, podendo assim, ter um aprendizado gratificante e significativo, promovendo assim atividades diferenciadas, que valorizem a construção de conceitos matemáticos, para que mais tarde essas crianças possam desenvolver suas habilidades com mais facilidade.

\section{Considerações Finais}

A pesquisa foi concluída com sucesso, onde se apresentou uma discussão sobre o processo de ensino da matemática na educação infantil por meio de estratégias lúdicas em sala de aula com a atualização de jogos e brincadeiras bem como ainda abordou a necessidade de implementar e cultivar tal metodologia, visto que a ludicidade é tida como diferencial de sucesso para a educação, permitindo as crianças o estímulo e encorajamento, favorecendo uma aprendizagem significativa e ao mesmo tempo leve e agradável, contribuindo para a transformação do modelo de escola monótona, por um ambiente mais acolhedor e prazeroso, em que o professor programa os objetivos de ensino e planejamento de metodologias que garantem a interação e a participação de modo divertido e excitante, em que se tem alegria em aprender.

Verificou-se também, que as atividades recreativas proporcionam experiências concretas integrando ação, pensamento e sentimento. Tais atividades podem ser uma brincadeira, um jogo, ou qualquer outra atividade que permite estabelecer uma relação com a 
ludicidade e o prazer. Ao permitir a fantasia, a alegria e a diversão proporciona uma aprendizagem através da alegria e do interesse de querer fazer espontaneamente.

Concluiu-se ainda que através da brincadeira, do jogo e das atividades lúdicas, as crianças se envolvem com profundidade nas ações propostas e sentem a necessidade de compartilhar com o outro, brincando e jogando a criança terá a oportunidade de desenvolver habilidades essenciais, estimulam a inteligência e desenvolve a criatividade, $o$ ato de brincar permite afeto e o envolvimento emocional, cognitivo de todo o processo de criatividade, estimulando a experiência, assim o lúdico, em parceria com a prática pedagógica é uma forma estimulante e enriquecedora para atingir uma totalidade no processo de aprendizagem.

\section{Referências}

ALSINA, i Pastells, Àngel. Desenvolvimento de competências matemáticas com recursos lúdico- manipulativos: para crianças de 6 a 12 anos: Metodologia/ Curitiba: Base Editora, 2009.

BRASIL, Ministério da Educação e do Desporto. Secretaria de Educação Fundamental. Referencial nacional para a educação infantil. Brasília: MEC/SEF, 1998.

Jogos infantis: O jogo a criança e a educação. Petrópolis: Vozes, 1993

BRASIL. MINISTÉRIO DA EDUCAÇÃO E DO DESPORTO. SECRETARIA DE EDUCAÇÃO FUNDAMENTAL. Referencial curricular nacional para a educação infantil: formação pessoal e social. Brasília: MEC/SEF, v.01 e 02.1998.43p.

BRASIL. MINISTÉRIO DA EDUCAÇÃO E DO DESPORTO. Disponível em: <http://portal.mec.gov.br/seb/arquivos/pdf/volume3.pdf >. Acesso em 05 de outubro de 2017.

BICUDO, M.A.V. Pesquisa em Educação Matemática. São Paulo: EDNESP, 1999.

BRASIL. Programa de Formação Inicial para Professores em Exercício na Educação Infantil - PROINFANTIL- (Org.) Karina Rizek Lopes, Roseane Pereira Mendes, Vitória Líbia Barreto de Faria. Brasília/MEC/SEB/SEED, v.02, unidade 5, 2005 43p.

KISHIMOTO, Tizuko Morchida (org.). Jogo, brinquedo, brincadeira e a educação. 10. Ed. São Paulo: Editora Cortez. 2007.

A séria busca no jogo: do lúdico na matemática .In:KISHIMOTO,T.M(org.). Jogo, brinquedo,brincadeira e a educação. São Paulo:Cortez, 2009. 
SOARES, Eduardo Sarquis. ensinar Matemática - desafios e possibilidades - Belo Horizonte: Dimensão, 2009.

\section{Como citar este artigo (Formato ABNT):}

SOUZA, Janiere R. de; FELIZARDO, João Everaldo A. Uma Análise da Aprendizagem da Matemática na Educação . Id on Line Revista Multidisciplinar e de Psicologia, 2017, vol.11, n.38, p.573-584. ISSN: 1981-1179.

Recebido: 01.10.2017

Aceito: 03.11.2017 